Canadian

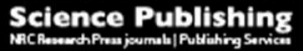

Botany

Botanique

\title{
Effect of linoleic acid on reproduction and yeast-mycelium dimorphism in the Dutch elm disease pathogens
}

\begin{tabular}{|r|l|}
\hline Journal: & Botany \\
\hline Manuscript ID & cjb-2015-0156.R1 \\
\hline Danuscript Type: & Article \\
\hline Complete List of Authors: & $\begin{array}{l}\text { Naruzawa, Erika Sayuri; Université Laval, Département de Sciences du Bois } \\
\text { et de la Forêt } \\
\text { Malagnac, Fabienne; Université Paris Sud, Institute for Integrative Biology } \\
\text { of the Cell (I2BC, UMR 9198) } \\
\text { Bernier, Louis; Université Laval, Département de Sciences du Bois et de la } \\
\text { Forêt }\end{array}$ \\
\hline Keyword: & fatty acid, <i>Ophiostoma</i>, yeast, hypha, perithecium \\
\hline & \\
\hline
\end{tabular}

SCHOLARONE $^{\text {m }}$

Manuscripts 
Effect of linoleic acid on reproduction and yeast-mycelium dimorphism in the Dutch elm disease pathogens

Erika Sayuri Naruzawa; Fabienne Malagnac; Louis Bernier

E. S. Naruzawa and L. Bernier. Université Laval, Faculté de foresterie, de géographie et de géomatique, Département des sciences du bois et de la forêt, Pavillon Charles-Eugène Marchand, Québec, Canada G1V OA6

F. Malagnac. Institute for Integrative Biology of the Cell (I2BC, UMR 9198), CEA, CNRS, Université Paris Sud, 91400 Orsay cedex, France

Corresponding author: Erika Sayuri Naruzawa (e-mail: erika-sayuri.naruzawa.1@ulaval.ca) 
1

2

3 Elm populations from North America and Europe were devastated by Dutch elm disease

4 (DED), a vascular disease caused by fungi from the genus Ophiostoma (Ascomycota).

5 These pathogens feature a yeast-mycelium dimorphism that may be related to virulence

6 by facilitating colonization of the host xylem. Cyclooxygenases (Cox) have been

7 proposed to modulate yeast-mycelium dimorphism of DED fungi, and homologs of Cox-

\section{Abstract}

encoding genes have been found in the nuclear genome of O. novo-ulmi subsp. novoulmi. Linoleic acid, a substrate for Cox, was reported to stimulate the formation of asexual and sexual reproduction structures in DED strains grown on complex media. We hypothesized that linoleic acid also induced mycelium production in liquid shake culture conditions. Linoleic acid was found to enhance production of reproductive structures in sexual crosses conducted on complex medium (elm sapwood agar) but was not sufficient for these structures to form on minimal medium. In liquid shake cultures grown in minimal medium, addition of linoleic acid stimulated mycelial formation. Our results suggest that linoleic acid plays a role in two complex pathways, reproduction and dimorphism, in the DED pathogens.

Keywords : Fatty acid, Ophiostoma, yeast, hypha, perithecium, morphological transition 
Résumé

25 Les populations d'ormes américains et européens ont été dévastées par la maladie 26 hollandaise de l'orme (MHO), une maladie vasculaire causée par des champignons 27 ophiostomatoïdes (Ascomycota). Ces agents pathogènes affichent un dimorphisme 28 levure-mycélium probablement lié à la virulence en facilitant la colonisation du xylème 29 de l'hôte. On a proposé antérieurement que des cyclooxygénases (Cox) modulent ce 30 dimorphisme. Des homologues de gènes cox sont présents dans le génome nucléaire 31 d'O. novo-ulmi subsp. novo-ulmi. L'acide linoléique, un substrat pour Cox, semble 32 stimuler la formation de structures de reproduction sexuée et asexuée chez les 33 ophiostomatoïdes sur milieux complexes. Nous avons émis l'hypothèse selon laquelle 34 l'acide linoléique induit la production de mycélium en milieux agités liquides. L'acide 35 linoléique a augmenté la production de structures de reproduction dans des croisements sexués sur milieu complexe (milieu au bois d'orme), mais pas sur milieu 37 minimum. En milieu minimum liquide agité, l'acide linoléique a stimulé la formation de mycélium. L'acide linoléique semble jouer un rôle dans les voies de reproduction et du dimorphisme chez ces champignons.

41 Mot-clés: Acide gras, Ophiostoma, levure, hyphe, perithèce, transition morphologique 
47 Successive pandemics of Dutch elm disease (DED) caused by Ophiostoma ulmi and O.

\section{Introduction}

novo-ulmi (Ascomycota) have inflicted massive losses to American and European elm populations (Santini et al. 2012). These pathogens exhibit yeast to mycelium dimorphism in which the yeast form is used for passive spread within xylem vessels of elm trees, whereas mycelium penetrates bordered pits and invades uninfected adjacent vessels. The mycelium form may also invade other cell types such as xylem parenchyma cells and fiber. Resistance of elms against DED appears to be, at least in part, related to the timing of defense mechanisms such as the production of tyloses and gels, as well as the synthesis and accumulation of phenolic compounds (Martin et al. 2007; Aoun et al. 2010). One consequence of rapid defense reactions may be the halting of yeast to hypha conversion, thus preventing invasive growth of DED fungi.

Several stimuli are known to control yeast to mycelium transition in shake liquid cultures of DED fungi. They include nitrogen source (Kulkarni and Nickerson 1981, Naruzawa and Bernier 2014), yeast cell concentration akin to quorum sensing (Kulkarni and Nickerson 1981, Hornby et al. 2004; Berrocal et al. 2012) and calcium-calmodulin interaction (Muthukumar and Nickerson 1984; Brunton and Gadd 1989; Gadd and Brunton 1992). According to Jensen et al. (1992), inhibitors of lipoxygenases (Lox) also interfere with yeast-mycelium transition and favor the production of yeast cells over mycelium. This was recently confirmed by Naruzawa and Bernier (2014) who further reported that salicylic acid, an inhibitor of cyclooxygenases (Cox), had a similar effect. 
Lox and Cox are dioxygenase enzymes that catalyze the synthesis of oxylipins by incorporating oxygen atoms into polyunsaturated fatty acids (PUFAs) (Bugg 2003). According to results by Jensen et al. (1992) and Naruzawa and Bernier (2014), oxylipins could be related to the yeast-mycelium transition of DED pathogens.

Oxylipins function as hormone signals to modulate timing and balance between sexual and asexual development and toxin production in fungi. According to Tstsigiannis et al. (2004a), an Aspergillus nidulans mutant in which the dioxygenase gene ppoC had been deleted exhibited increased sexual spore production and decreased asexual spore formation. The opposite response occurred in the case of an $A$. nidulans $\triangle p p o A$ mutant (Tsistigiannis et al 2004b). An A. nidulans $\triangle p p o \mathrm{~A}, \Delta p p o \mathrm{~B}$ and $\Delta p p o \mathrm{C}$ triple mutant was unable to produce sterigmatocystin, a precursor of aflatoxin, both in vivo and in planta. On the other hand, this mutant overproduced penicillin (Tsitsigiannis and Keller 2006). Also, the impaired mutant could no longer colonize peanut seeds. The latter phenotype could be explained by decreased conidiation and lipase enzyme production (Tsitsigiannis and Keller 2006). In contrast, an A. fumigatus $\Delta p p o \mathrm{~A}, \Delta p p o \mathrm{~B}$ and $\Delta p p o \mathrm{C}$ triple mutant was hypervirulent in the invasive pulmonary aspergillosis murine model system and had tolerance to hydrogen peroxide, which implicates resistance to reactive oxygen species defense of host (Tsitsigiannis et al. 2005). Therefore, these enzymes and oxylipins are involved in the regulation of fungal metabolism. Interestingly, homologs of ppo genes are found in the Ophiostoma novo-ulmi genome (Comeau et al., 2015; Naruzawa et al. unpublished). 
91 Linoleic acid was reported by Calvo et al. (1999) to regulate asexual and sexual spore

92 production in $A$. flavus, $A$. parasiticus and $A$. nidulans in a way similar to oxylipins

93 produced by Ppo dioxygenases. In the DED pathogens, addition of linoleic acid to a

94 complex growth medium (potato dextrose agar) was found to induce the formation of 95 asexual spore bearing structures called synnemata (formerly known as coremia) 96 (Hubbes 1975). Furthermore, Hubbes et al. (1977) observed a high concentration of 97 linoleic acid in elm sapwood and bark in June, and a decrease of this PUFA in 98 heartwood. This would support the involvement of linoleic acid in the production of 99 synnemata, since the latter are found in elm bark beetle breeding galleries under the 100 bark (Hubbes et al. 1977). Linoleic acid also favored the production of sexual spore101 bearing structures (perithecia) in complex media such as agar media containing hot 102 water extracts of American elm wood, American elm leaves, green tea or black tea 103 (Marshall et al. 1982).

105 Based on the above results, we speculated that linoleic acid was involved in the 106 reproduction and yeast-mycelium dimorphism of DED pathogens. Our specific 107 objectives were to verify whether linoleic acid stimulated the formation of asexual and 108 sexual reproductive structures on defined solid growth media and enhanced the 109 production of mycelium in liquid shake cultures.

\section{Materials and Methods}

\section{Fungal strains}


114 Strains used in this study were retrieved from the CEF (Centre d'Étude de la Forêt) 115 fungal collection at Université Laval, Québec, Canada 116 (http://www.cef.ulaval.ca/index.php?n=CEF.CollectionsChampignonsPathogenes).

117 These included O. ulmi Q412T (Mat1-1) and W9 (Mat1-2), O. novo-ulmi subsp. novo118 ulmi H327 (Mat1-1) and F5-28 (Mat1-2), and O. novo-ulmi subsp. americana VA3O 119 (Mat1-1) and NRRL6404 (Mat1-2). Strains were grown on an orbital shaker (110 rev $120 \mathrm{~min}-1)$ at room temperature $\left(24-25^{\circ} \mathrm{C}\right)$ in $125-\mathrm{mL}$ Erlenmeyer flasks that contained 50 $121 \mathrm{~mL}$ liquid Ophiostoma minimal medium (OMM; Bernier and Hubbes 1990) with $10 \mathrm{mM}$ 122 addition of proline (L-proline; Sigma Aldrich, St. Louis, USA) to promote yeast cell 123 formation (Kulkarni and Nickerson 1981; Naruzawa and Bernier 2014).

127 Production of reproductive structures was assessed by setting up sexual crosses on a 128 defined medium and a complex one. The former was solid OMM with ammonium 129 sulphate as nitrogen source, whereas the latter consisted in elm sapwood agar (ESA) 130 prepared according to Brasier (1981). Fungal strains were first cultured on MEA (Malt 131 extract agar, Oxoid, Nepean, Canada). In order to proceed with crosses, recipient 132 strains were grown on unamended solid OMM or ESA, or on solid OMM or ESA 133 supplemented with linoleic acid (Sigma Aldrich) at $6 \mu \mathrm{L} \mathrm{mL}^{-1}$. Once mycelial colonies had 134 covered the entire plate (7-10 days), they were fertilized with 1-ml aliquots of yeast cell 
135 suspensions of donor isolates grown in shake liquid OMM supplemented with proline.

136 Three pairs of sexually compatible strains were used in reciprocal crosses, for a total of

137 six combinations (Table 1). Each combination included 6 repetitions (a Petri dish was

138 considered a repetition). Cultures were kept in an incubator at $23-24^{\circ} \mathrm{C}$ in the dark.

139 Plates were examined for the presence of synnemata, protoperithecia and perithecia, 140 starting at 8 days after fertilization until 60 days after fertilization. The experiment was 141 conducted twice or three times.

Effect of linoleic acid on yeast-mycelium transition

145 The effect of linoleic acid on dimorphism was tested in liquid OMM supplemented with 146 proline or arginine (L-arginine monohydrochloride, Sigma Aldrich) as nitrogen source.

147 Linoleic acid or sterile distilled water (control) was added aseptically to the media at $6 \mu \mathrm{L}$ $148 \mathrm{~mL}^{-1}$ after autoclaving $\left(121^{\circ} \mathrm{C}\right.$ for 20 minutes $)$. Six-day old shake cultures grown in OMM 149 supplemented with proline (stationary phase) of strains W9, H327, VA3O or NRRL6404 150 were used to inoculate test media to a final concentration of $2 \times 10^{7}$ spores $\mathrm{mL}^{-1}$. 151 Samples were incubated on an orbital shaker (110 rev min-1) at room temperature (24$\left.15225^{\circ} \mathrm{C}\right)$. Yeast cells and mycelia were harvested by repeated sampling after 19 and 24 153 hours of incubation. For each incubation time, photographs were taken for each 154 repetition with an Evolution VF digital color camera (Media Cybernetics, Rockville, USA) 155 mounted on a Olympus BX41 (Tokyo, Japan) light microscope and analyzed with the 156 software Q Capture Pro version 5.1.1.14 (Qimaging, Surrey, Canada). At least 100 157 fungal structures (yeast or hypha) were counted for each repetition. A spore with an 
158 emergent hypha longer than the length of the spore diameter was counted as mycelium. 159 Each treatment included five repetitions. The proportion of mycelia-yeast was calculated 160 for each repetition. The experiment was conducted twice.

162 Statistical analysis of yeast-mycelium transition in liquid cultures

164 Treatments were arranged in a completely randomized design. Experiments on yeast165 mycelium transition, which involved more than one sampling time, were treated as 166 repeated measures. PROC GLM with « repeated» command was used on SAS 167 software version 9.1 (SAS Institute, Cary, USA). Since the interaction with the time of 168 sampling was significant, a separate post-hoc analysis (t-test) was conducted for each 169 time and each strain for the control and the treatment.

171 Results

173 Effect of linoleic acid on the formation of reproductive structures

175 No reproductive structures (synnemata, protoperithecia or perithecia) were observed in 176 sexual crosses conducted on unamended solid OMM nor on solid OMM supplemented 177 with linoleic acid (Table 1). Unamended ESA medium induced a variety of responses in 
178 the sexual crosses tested. Protoperithecia and perithecia were observed in the $\mathrm{H} 327$ 웅 179 (recipient) $\times \mathrm{F} 5-28 \AA$ (donor) cross, as well as in the reciprocal $\mathrm{F} 5-28 \bigcirc \times \mathrm{H} 327 \AA$ cross. 180 In the former cross few perithecia were reported. Synnemata and protoperithecia were 181 observed in the NRRL6404 9 x VA3O $\bigcirc$ cross, as well as in the reciprocal cross VA30 $q$

$182 \times$ NRRL6404 $⿱$. However, very few reproductive structures (around five of each per petri 183 dish) were observed in the latter. Synnemata, protoperithecia and perithecia were 184 produced in crosses between strains Q412T and W9, irrespective of which strain was 185 used as recipient or donor.

187 Solid ESA supplemented with linoleic acid induced the formation of reproductive 188 structures in all crosses tested. On this medium, synnemata, protoperithecia and 189 perithecia were formed in all crosses. Synnemata, protoperithecia and perithecia were 190 observed in the NRRL6404 9 x VA30 $\bigcirc$ cross; however very few reproductive structures 191 (five or less of each per petri dish) occurred in the VA3O 9 x NRL6404 ${ }^{\lambda}$ reciprocal 192 cross, with protoperithecia and perithecia observed in only one of three separate 193 experiments. Typical synnemata, perithecia and protoperithecia produced by O. ulmi 194 and O. novo-ulmi on ESA media are shown in Figure 1. 
198 Linoleic acid stimulated mycelium production in DED strains grown in shake liquid 199 culture, including O. ulmi strain W9 which is strongly committed to yeast cell production 200 even when exposed to mycelium-inducing conditions such as incubation in OMM in the 201 presence of ammonium sulfate or arginine as nitrogen sources (Naruzawa and Bernier 202 2014). Increases in mycelium production in response to linoleic acid were statistically 203 significant for all strains incubated for 24 hours in the presence of arginine (Fig. 2A) or 204 proline (Fig. 2B) as nitrogen sources. However, observations made after 19 hours of 205 incubation showed that addition of linoleic acid consistently increased mycelium 206 production in all strains, except W9, in arginine-containing media, whereas it induced a 207 significant response in all four strains tested in proline-containing media.

\section{Discussion}

211 Dutch elm disease fungi exhibit a yeast-mycelium dimorphism which may be related to 212 virulence. They produce yeast cells in order to spread within xylem vessels of elms, 213 while the mycelium morphology allows them to penetrate and invade uninfected 214 adjacent vessels as well as xylem parenchyma cells and fiber. Delay in the transition 215 from yeasts to hyphae could result in halting of the pathogen as timing for the 216 production of tyloses and gels, and synthesis and accumulation of phenolic compounds 217 appears to be essential for plant defense (Martin et al. 2007; Aoun et al. 2010). The 218 transition from hyphae to yeasts also appears to be crucial for virulence. A spontaneous 219 mutant of O. novo-ulmi, in which conversion from hyphae to yeasts was blocked, failed 
220 to induce DED symptoms when inoculated to Ulmus americana (Richards 1994).

221 Therefore, conversions from yeasts to hyphae and from hyphae to yeasts could both be

222 implicated in virulence of the DED fungi.

223

224 Yeast-to-hyphae dimorphism seems to be controlled, at least in part, by dioxygenases

225 since inhibitors of lipoxygenases and cyclooxygenases affect this transition in DED

226 pathogens according to our previous study (Naruzawa and Bernier 2014).

227 Dioxygenases oxidize polyunsaturated fatty acids (PUFAs) to produce oxylipins (Bugg

228 2003). The PUFA linoleic acid is a substrate for cyclooxygenases and a precursor of

229 oxylipins. One can therefore speculate that linoleic acid is involved in mycelium

230 production since inhibition of cyclooxygenases, and subsequently of oxylipins, disturbs

231 yeast-to-hyphae transition in the DED pathogens.

233 Linoleic acid is known to induce asexual (synnemata) and sexual (perithecia) bearing 234 structures in Ophiostoma species. Neumann and Hubbes (1972) observed that the 235 sapstain fungus 0 . piceae produced the greatest number of synnemata in media 236 supplemented with sapwood extracts from balsam fir (Abies balsamea). These authors 237 established that linoleic acid was the compound responsible for the stimulation of 238 asexual reproduction in this fungus. Hubbes (1975) later reported that, among many 239 terpenes and unsaturated fatty acids he had tested, linoleic acid and its esthers were 240 the most active in stimulating the production of synnemata in the DED pathogens. 241 Moreover, formation of perithecia in the DED pathogens was triggered by fatty acids in 242 agar media with extracts of American elm wood, American elm leaves, and green and 
243 black tea, according to Marshall et al. (1982). These authors also reported that 244 abundant perithecia were obtained on a medium containing only the extract of black tea, 245 linoleic acid, and pyridoxine.

247 In this study, we corroborated the effect of linoleic acid on synnemata and perithecia 248 production in DED pathogens observed by Hubbes (1975) and Marshall et al. (1982) in 249 complex media (OCM). Based on our observations, no reproductive structures occurred 250 on synthetic medium without elm wood (OMM). Neumann and Hubbes (1972) had 251 previously verified that 0 . piceae produced no synnemata on a poor medium (water 252 agar) or on media containing heartwood extracts. It thus seems that a signal from the 253 plant, specifically from the sapwood, is necessary for the formation of perithecia and 254 synnemata in ophiostomatoid fungi. Hubbes et al. (1977) reported a high concentration 255 of linoleic acid in elm sapwood and bark in June (the period when elms are most 256 susceptible to DED in the northern hemisphere) and a decrease in the concentration of 257 this product in heartwood. Linoleic acid was thus pointed out as the compound that 258 favors formation of reproductive structures. Marshall et al. (1982) hypothesized that elm 259 phenolics were also involved in perithecia formation. However, results from an earlier 260 study by Holmes (1970) contradict this exclusivity of plant compounds in triggering 261 perithecia formation. This researcher verified that perithecia of DED pathogens were 262 formed in four out of eight variations of Zentmyer-Tchernoff synthetic media (glucose, 263 asparagine, $\mathrm{KH}_{2} \mathrm{PO}_{4}, \mathrm{MgSO}_{4} .7 \mathrm{H}_{2} \mathrm{O}, \mathrm{ZnSO}_{4}, \mathrm{FeCl}_{3}$, pyridoxine, thiamine, and agar), 264 although numbers were low and inconsistent, as pointed out by Marshall et al. (1982). 265 On the other hand, we conducted crosses differently compared to Holmes (1970). We 
266 seeded the recipient strain ( $q$ cultivated on solid media) with the donor strain ( $\delta$ from

267 liquid OMM), whereas Holmes (1970) conducted crosses by placing a plug of culture of

268 each fungal partner at $1 \mathrm{~cm}$ from each other (adjacent inoculation) on the Zentmyer-

269 Tchernoff synthetic media. It is possible that some compounds which influenced

270 production of sexual structures were present in the plug of parental agar cultures used

271 by Holmes (1970) for crosses on synthetic media. This could explain the low and 272 inconsistent production of these structures in the latter study.

274 All the crosses we examined on ESA amended with linoleic acid bore abundant 275 perithecia except for the cross VA3O 9 x NRRL6404 $\curvearrowright$. These strains were expected to 276 cross with each other since they both belong to O. novo-ulmi subsp. americana 277 (Naruzawa and Bernier 2014) and originate from the USA. Holmes (1970) explained the 278 lack of perithecia in some crosses of DED pathogens as a failure of gametangial contact 279 which is required for the formation of ascocarps. Further incompatibility between 280 VA3O 9 X NRL6404 ${ }^{\wedge}$ was observed in our study as none to few reproductive 281 structures were seen on unamended ESA medium. However, in the reciprocal cross, 282 NRRL6404 + x VAO ${ }^{\AA}$, synnemata and protoperithecia were abundant on ESA. This 283 points out a malfunction of sexual reproduction in cross VA3O年 $x$ NRRL6404. 284 Possibly, VA3O could not act as a receptor for reproduction and NRRL6404 as a 285 donnor. In the study conducted by Holmes (1977), an isolate from the Netherlands 286 acted only as male (donor) but kept its pathogenicity towards elm. The author argued 287 that this strain had lost its hermaphroditic capacity after three months of laboratory 
288 transfers. In our case, the cultures were grown for only one to two weeks on MEA after 289 they had been recovered from storage at $-80^{\circ} \mathrm{C}$.

291 We observed a significant effect of linoleic acid on mycelium production in liquid 292 cultures of DED pathogens. To the best of our knowledge, it is the first time this PUFA is 293 associated with yeast to mycelium conversion in these fungi. Previously, a similar effect 294 on yeast-mycelium dimorphism of DED strains was reported for yeast extract (Brunton 295 and Gadd, 1989; Brunton and Gadd 1991; Naruzawa and Bernier 2014). The latter is a 296 complex product which concentrates the water soluble portion of Saccharomyces 297 cerevisiae cells that have been autolyzed. According to the manufacturer (BD 298 Diagnostics, Sparks, MD, USA), yeast extract provides essential water soluble vitamins, 299 amino acids, peptides and carbohydrates. Germ tubes of O. novo-ulmi induced by yeast 300 extract exhibit increased uptake of $\mathrm{Ca}^{2+}$ compared to uptake by other cell types 301 (Brunton and Gadd 1991). Yeast-mycelium transition with yeast extract was 302 accompanied by increased intracelular concentration of cAMP in O. novo-ulmi (Brunton 303 and Gadd 1989). According to these authors, addition of nucleotides and nucleosides 304 caused a similar response but to a lesser extent compared to yeast extract. Inosine 305 caused the largest response among the nucleotides tested. Thus, Brunton and Gadd 306 (1989) could not explain whether the yeast extract effect on mycelium induction of $O$. 307 novo-ulmi was due to the presence of nucleotides and nucleosides in this complex 308 product. 
310 Linoleic acid, on the other hand, is a simple molecule, a polyinsaturated fatty acid

311 involved in prostaglandin synthesis. The results obtained here indicate that this fatty

312 acid, and possibly products derived from it, is directly related to dimorphism. This, in

313 turn, suggests that the pathways for the production of prostaglandins (eg. oxylipins)

314 control, at least in part, the dimorphism of DED fungi. Arginine also induces mycelium

315 production (Kulkarni and Nickerson 1981; Naruzawa and Bernier 2014) in DED fungi.

316 After $19 \mathrm{~h}$ of incubation in liquid OMM supplemented with arginine, a strain (W9) did not

317 respond to linoleic acid induction of mycelium. It could be that arginine masked the

318 effect of linoleic acid on yeast-mycelium dimorphism in W9. After $24 \mathrm{~h}$ of incubation, the

319 effect of linoleic acid on mycelium induction was clearer. Possibly, after this period,

320 linoleic acid was consumed by cells grown in OMM supplemented with arginine and

321 hyphae were induced. Arginine may disturb the linoleic acid effect and interact with this

322 PUFA in an unknown way in young (less than 24-hour old) cultures of W9.

323 Lipids have been associated with yeast to hyphae dimorphism in other fungal species.

324 According to Ito et al. (1982), an increase in the lipid synthesis rate was accompanied

325 by yeast to hypha transition when Mucor racemosus was transferred from anaerobic to 326 aerobic conditions. This transition was not detected when cerulenin, an antibiotic that 327 inhibits fatty acid synthase and then lipid synthesis (Sanadi et al. 1987), was added to 328 the media under aerobic conditions. This suggests that lipid synthesis is correlated to $M$. 329 racemosus dimorphism. Nevertheless, cerulenin inhibited also ornithine decarboxylase 330 activity, RNA and protein synthesis (Ito et al. 1982). 
332 Another indication that lipids are connected to dimorphism was provided by the study of 333 Zinjarde et al. (2008). Optimal (60\%) formation of mycelia in Yarrowia lipolytica was 334 obtained with coconut oil or palm kernel oil, whereas suboptimal (40\%) mycelium 335 formation was induced with peanut oil, olive oil, or sesame oil (Zinjarde et al. 2008). 336 Major fatty acids present in coconut and palm kernel oil are lauric acid (45-48\%) and 337 myristic acid (18\%) (Mlícková et al. 2004). While myristate was not effective for 338 dimorphic transition (32\%), the authors obtained $51 \%$ of the cells in mycelial form with 339 laurate. In addition, they observed that a combination of laurate and myristate in a ratio 340 of $2.6: 1$ enhanced mycelium formation to $65 \%$. Longer chain saturated fatty acids 341 (potassium palmitate or stearate) or oleic acid stimulated the yeast form of Y. lipolytica.

343 Farnesol, an oxylipin, plays a crucial role in the density-dependent dimorphism in 344 Candida albicans (Nickerson et al. 2012). This phenomenon is also known as quorum 345 sensing. According to Hornby et al. (2001), the quorum sensing molecule farnesol halts 346 the mycelial phase at $10^{6}$ cells $\mathrm{ml}^{-1}$ in liquid culture. In addition, a metabolite derived 347 from linoleic acid by $\beta$-oxydation, 3(R)-hydroxytetradecanoic acid, participates in the 348 quorum sensing mechanism increasing germ tube and biofilm formation (Nigam et al. 349 2011). This metabolite upregulates the CAP1 gene, which encodes an adenylate 350 cyclase-associated protein involved in the formation of Cap protein as well as hyphal 351 wall protein 1 (Hwp1), involved in the regulation of filamentous growth (Nigam et al. 352 2011). 
354 Ophiostoma novo-ulmi also features a yeast-mycelium dimorphism controlled by 355 quorum sensing (Hornby et al. 2004). Isoleucine 2-methyl-1-butanol, a fusel alcohol, 356 was demonstrated by Berrocal et al. (2012) to be responsible for the density dependent 357 dimorphism behaviour of this DED pathogen. In concentrations higher than $2 \times 10^{7}$ 358 spores $\mathrm{mL}^{-1}$ this molecule seems to be responsible for the yeast morphology that is the 359 predominant growth form within these concentrations (Hornby et al. 2004). A correlation 360 between S. cerevisiae cells enriched with linoleic and linolenic acid and wine fermented samples richer in fusel alcohols was observed by Rosi and Bertuccioli (1992). In contrast, Thurston et al. (1981) observed a reduction in the production of esthers (60$75 \%)$ and fusel alcohols (69-84\%) by the yeast in beer when linoleic acid was added.

364 Thus, it is possible that the density dependent phenomenon in 0 . novo-ulmi is 365 connected to fatty acid uptake by the fungus.

A link between sexual differentiation signaled by mating pheromones and regulation of 368 dimorphism seems to take place in fungi since both features share signalling 369 components. For the corn smut pathogen, Ustilago maydis, these caracteristics are also connected to plant invasion (Klosterman et al. 2007; Brefort et al. 2009). Mating and

371 dimorphism are linked by mitogen activated protein (MAP) kinase cascades as verified 372 for U. maydis and S. cerevisiae (Madhani and Fink 1998; Klosterman et al. 2007; 373 Brefort et al. 2009). There is an interplay between the MAP kinase pathway and the 374 cyclic adenosine monophosphate (cAMP) pathway to regulate the dimorphism and 375 mating in these fungi. The filamentous growth of diploid cells, invasive growth of haploid 376 cells in culture media and mating pheromone response are controlled by the same four 
377 MAP kinase pathway components (protein kinases Ste20p, Ste11p and Ste7p, and 378 transcription factor Ste12p) in S. cerevisiae (Madhani and Fink 1998). As well, MAP 379 kinase cascade components such as Kpp4/Ubc4, Fuz7/Ubc5, and Kpp2/Ubc3 are 380 shared in U. maydis for mating, conversion from yeast-to-hypha and invasion of the 381 plant (Sánchez-Martínez and Pérez-Martín 2001; Brefort et al. 2009).

A homolog to cyclooxygenases in Magnaporthe oryzae, 10R-Dox-Eas, was recently 384 discovered by Hoffmann et al. (2014). The biological function of this cyclooxygenase385 like protein is unknown in M. oryzae. On the other hand, Soanes et al. (2012) verified 386 that the gene that encodes this protein is up-regulated during the early and late phases 387 of appressorium formation and down-regulated by gene deletion of the MAP kinase PMK1. Moreover, homologs of this M. oryzae protein regulated by a MAP kinase are found in plant pathogenic fungi, which indicates a possible link between this protein and pathogenicity (Hoffmann et al. 2014). Interestingly, we found the presence of a homolog of 10R-Dox-Eas and PpoA in the DED agents (Naruzawa et al. unpublished).

Mating and dimorphism may thus also be interconnected in the DED pathogens.

394 Linoleic acid, other fatty acids and their products would regulate these features. These 395 results reinforce the relevant link between reproduction, dimorphism control and 396 virulence in DED fungi. Research needs to be directed to the above fitness 397 characteristics in order to design efficient DED control approaches. One such approach 398 could target fatty acid regulation or their inhibition to prevent reproduction, dimorphism 
399 and, subsequently, higher virulence in these fungi. As the genome of the agressive 0.

400 novo-ulmi subsp. novo-ulmi strain H327 was recently sequenced (Forgetta et al. 2013)

401 and annotated (Comeau et al. 2015), studies of genes implicated in dimorphism, 402 virulence, reproduction and other fitness features are facilitated. Furthermore, these 403 results could be used as a model for studies of other ophiostomatoid fungi and 404 pathogenic Ascomycetes.

405

406 Acknowlegdements

407 This work was supported by the Natural and Engineering Research Council (NSERC) of 408 Canada and Fonds de recherche du Québec-Nature et technologies (FRQNT).

\section{References}

411 Aoun, M., Jacobi, V., Boyle, B., Bernier, L. 2010. Identification and monitoring of Ulmus

412 americana transcripts during in vitro interactions with the Dutch elm disease pathogen

413 Ophiostoma novo-ulmi. Physiol. Mol. Plant Pathol. 74(3): 254-266.

415 Bernier, L., and Hubbes, M. 1990. Mutations in Ophiostoma ulmi induced by N-methyl-

416 N'-nitro-N-nitrosoguanidine. Can. J. Bot. 68(2):225-231 
418 Berrocal, A., Navarrete, J., Oviedo, C., Nickerson, K.W. 2012. Quorum sensing activity 419 in Ophiostoma ulmi: effects of fusel oils and branched chain amino acids on yeast420 mycelial dimorphism. J. Appl. Microbiol. 113(1): 126-134.

421

422 Brasier, C.M. 1981. Laboratory investigation of Ceratocystis ulmi. In Compendium of 423 Elm Diseases. Edited by R. J. Stipes and R. J. Campana. American Phytopathological 424 Society, St Paul, Minn, pp. 76-79

426 Brefort, T., Doehlemann, G., Mendoza-Mendoza, A., Reissmann, S., Djamei, A., 427 Kahmann, R. 2009. Ustilago maydis as a pathogen. Annu. Rev. Phytopathol. 47: 423428445.

Brunton, A.H., and Gadd, G.M. 1989. The effect of exogenously-supplied nucleosides 431 and nucleotides and the involvement of adenosine 3':5'-cyclic monophosphate (cyclic 432 AMP) in the yeast mycelium transition of Ceratocystis (= Ophiostoma) ulmi. FEMS 433 Microbiol. Lett. 60(1): 49-53.

435 Brunton, A.H., and Gadd, G.M. 1991. Evidence for an inositol lipid signal pathway in the 436 yeast-mycelium transition of Ophiostoma ulmi, the Dutch elm disease fungus. Mycol. 437 Res. 95(4): 484-491. 
439 Bugg, T.D.H. 2003. Dioxygenase enzymes: catalytic mechanisms and chemical models.

440 Tetrahedron 59(36): 7075-7101.

441

442 Calvo, A.M., Hinze, L.L., Gardner, H.W., Keller, N.P. 1999. Sporogenic effect of 443 polyunsaturated fatty acids on development of Aspergillus spp. Appl. Environ. Microbiol. 444 65(8): 3668-3673.

445

446 Comeau, A.M., Dufour, J., Bouvet, G.F., Jacobi, V., Nigg, M., Henrissat, B., Laroche, J.,

447 Levesque, R.C., Bernier, L. 2015. Functional annotation of the Ophiostoma novo-ulmi 448 genome: insights into the phytopathogenicity of the fungal agent of Dutch elm disease.

449 Genome Biol. Evol. 7(2):410-430.

450

451 Forgetta, V., Leveque, G., Dias, J., Grove, D., Lyons, Jr.R., Genik, S., Wright, C., Singh,

452 S., Peterson, N., Zianni, M., Kieleczawa, J., Hintz, W., Jacobi, V., Bernier, L., Levesque, 453 R., Dewar, K. 2013. Comparison of multiple genome sequencing centers and analysis 454 of the Dutch elm disease fungus genome using the Roche/454 GS-FLX Titanium 455 system. J. Biomol. Tech. 24: 39-49. 
457 Gadd, G.M., and Brunton, A.H. 1992. Calcium involvement in dimorphism of 458 Ophiostoma ulmi, the Dutch elm disease fungus, and characterization of calcium uptake 459 by yeast cells and germ tubes. J. Gen. Microbiol. 138(8): 1561-1571.

461 Hoffmann, I., Jernerén, F., Oliw, E.H. 2014. Epoxy alcohol synthase of the rice blast 462 fungus represents a novel subfamily of dioxygenase-cytochrome P450 fusion enzymes. 463 J. Lipid. Res. 55(10): 2113-2123.

Holmes, F.W. 1970. Formation of perithecia of Ceratocystis ulmi on natural and synthetic nutrient media. Neth. J. Plant. Pathol. 76(3): 129-134.

468 Holmes, F.W. 1977. Distinction between sex and compatibility in Ceratocystis ulmi, as 469 shown by unisexual male cultures. Mycologia. 69(6): 1149-1161.

471 Hornby, J.M., Jensen, E.C., Lisec, A.D., Tasto, J.J., Jahnke, B., Shoemaker, R., 472 Dussault, P., Nickerson, K.W. 2001. Quorum sensing in the dimorphic fungus Candida 473 albicans is mediated by farnesol. Appl. Environ. Microbiol. 67(7): 2982-2992.

475 Hornby, J.M., Jacobitz-Kizzier, S.M., McNeel, D.J., Jensen, E.C., Treves, D.S., 476 Nickerson, K.W. 2004. Inoculum size effect in dimorphic fungi: extracellular control of 
477 yeast-mycelium dimorphism in Ceratocystis ulmi. Appl. Environ. Microbiol. 70(3): 13564781359.

479

480 Hubbes, M.1975. Terpenes and unsaturated fatty acids trigger coremia formation by 481 Ceratocystis ulmi. Eur. J. Forest. Pathol. 5(3): 129-137.

483 Hubbes, M., Neumann, P., Willemot, C.1977. Fatty acids triggering coremia formation 484 by Ceratocystis ulmi their occurrence and distribution in elm wood. Eur. J. Forest. 485 Pathol. 7(2): 98-104.

487 Ito, E., Cihlar, R.L., Inderlied, C.D.1982. Lipid synthesis during morphogenesis in Mucor 488 racemosus. J. Bacteriol. 152(2): 880-887.

490 Jensen, E.C., Ogg, C., Nickerson, K.W. 1992. Lipoxygenase inhibitors shift the 491 yeast/mycelium dimorphism in Ceratocystis ulmi. Appl. Environ. Microbiol. 58(8): 25054922508.

494 Klosterman, S.J., Perlin, M.H., Garcia-Pedrajas, M., Covert, S.F., Gold, S.E. 2007. 495 Genetics of morphogenesis and pathogenic development of Ustilago maydis. Adv. 496 Genet. 5: 1-47. 
498 Kulkarni, R.K., and Nickerson, K.W. 1981. Nutritional control of dimorphism in 499 Ceratocystis ulmi. Exp. Mycol. 5(2):148-154.

500

501 Madhani, H.D., and Fink, G.R.1998. The control of filamentous differentiation and 502 virulence in fungi. Trends Cell Biol. 8(9): 348-353.

504 Marshall, M.R., Hindal, D.F., MacDonald, W.L.1982. Production of perithecia in culture 505 by Ceratocystis ulmi. Mycologia, 74(3): 376-381.

506

507 Martín, J.A., Solla, A., Woodward, S., Gil, L. 2007. Detection of differential changes in 508 lignin composition of elm xylem tissues inoculated with Ophiostoma novo-ulmi using 509 Fourier transform-infrared spectroscopy. For. Pathol. 37(3): 187-191.

510

511 Mlícková, K., Roux, E., Athenstaedt, K., d’Andrea, S., Daum, G., Chardot, T., Nicaud, 512 J.M. 2004. Lipid accumulation, lipid body formation, and acyl coenzyme A oxidases of 513 the yeast Yarrowia lipolytica. Appl. Environ. Microbiol. 70(7): 3918-3924. 
515 Muthukumar, G., and Nickerson, K.W. 1984. Ca(II)-calmodulin regulation of fungal 516 dimorphism in Ceratocystis ulmi. J. Bacteriol. 159(1): 390-392.

518 Naruzawa, E.S., and Bernier, L. 2014. Control of yeast-mycelium dimorphism in vitro in 519 Dutch elm disease fungi by manipulation of specific external stimuli. Fungal Biol. 520 118(11):872-884.

521

522 Neumann, P., and Hubbes, M.1972. Factor in Abies balsamea responsible for coremia 523 formation of Ceratocystis piceae. Eur. J. Forest. Pathol. 2(4): 215-229.

525 Nickerson, K.W., Atkin, A.L., Hargarten, J.C., Pathirana, R., Hasim, S. 2012. Thoughts 526 on quorum sensing and fungal dimorphism. In: Biocommunication of Fungi. Edited by G. 527 Witzany. Springer Netherlands, Dordrecht, ZH. pp.189-204.

528

529 Nigam, S., Ciccoli, R., Ivanov, I., Sczepanski, M., Deva, R. 2011. On mechanism of 530 quorum sensing in Candida albicans by 3 (R)-hydroxy-tetradecaenoic acid. Curr. 531 Microbiol. 62(1): 55-63.

533 Richards, W.C. 1994. Nonsporulation in the Dutch elm disease fungus Ophiostoma 534 ulmi: evidence for control by a single nuclear gene. Can. J. Bot. 72(4): 461-467. 
536 Rosi, I., and Bertuccioli, M. 1992. Influences of lipid addition on fatty acid composition of 537 Saccharomyces cerevisiae and aroma characteristics of experimental wines. J. Inst. 538 Brew. 98(4): 305-314.

540 Sanadi, S., Pandey, R., Khuller, G.K. 1987. Reversal of cerulenin induced inhibition of 541 phospholipids and sterol synthesis by exogenous fatty acids/sterols in Epidermophyton 542 floccosum. Biochim. Biochim. Biophys. Acta. 921(2):341-346.

544 Sánchez-Martínez, C., and Pérez-Martín, J. 2001. Dimorphism in fungal pathogens: 545 Candida albicans and Ustilago maydis-similar inputs, different outputs. Curr. Opin. 546 Microbiol. 4(2): 214-221.

548 Santini, A., Pecori, F., Pepori, A., Brookes, A., 2012. 'Morfeo' Elm: a new variety 549 resistant to Dutch elm disease. Forest Pathol. 42(2): 171-176.

551 Soanes, D.M., Chakrabarti, A., Paszkiewicz, K.H., Dawe, A. L., Talbot, N.J. 2012.

552 Genomewide transcriptional profiling of appressorium development by the rice blast 553 fungus Magnaporthe oryzae. PLoS Pathog. 8(2): e1002514. 
555 Thurston, P.A., Taylor, R., Ahvenainen, J. 1981. Effects of linoleic acid supplements on

556 the synthesis by yeast of lipids and acetate esters. J. Inst. Brew. 87(2): 92-95.

557

558 Tsitsigiannis, D. I., Keller, N.P. 2006. Oxylipins act as determinants of natural product

559 biosynthesis and seed colonization in Aspergillus nidulans. Mol. Microbiol. 59(3):882-

$560 \quad 892$.

561

562 Tsitsigiannis, D.I., Kowieski, T.M., Zarnowski, R., Keller, N.P. 2004a. Endogenous

563 lipogenic regulators of spore balance in Aspergillus nidulans. Eukaryot. Cell. 3(6):13985641411.

565

566 Tsitsigiannis, D.I., Zarnowski, R., Keller, N.P. 2004b. The lipid body protein, Ppoa, 567 coordinates sexual and asexual sporulation in Aspergillus nidulans. J. Biol. Chem. $568 \quad 279(12): 11344-11353$.

570 Tsitsigiannis, D.I., Bok, J.W., Andes, D., Nielsen, K.F., Frisvad, J.C., Keller, N.P. 2005.

571 Aspergillus cyclooxygenase-like enzymes are associated with prostaglandin production 572 and virulence. Infect. Immun. 73(8): 4548-4559. 
574 Zinjarde, S.S., Kale, B.V., Vishwasrao, P.V., Kumar, A.R. 2008. Morphogenetic 575 behavior of tropical marine yeast Yarrowia lipolytica in response to hydrophobic

576 substrates. J. Microbiol. Biotech. 18(9): 1522-1528.

577

578

579

580

581

582

583

584

585

586

587

588

589

590 
591 Table 1. Production of reproductives structures in crosses of Ophiostoma novo-ulmi 592 subsp. novo-ulmi, O.novo-ulmi subsp. americana and O. ulmi on four solid media*. 593 Abbreviations: Protoperithecia $=\mathrm{PP}$, Perithecia $=\mathrm{P}$, Synnemata $=\mathrm{S}$.

\begin{tabular}{llll}
\hline Crosses & $\mathrm{OMM+}$ & $\mathrm{OMM}+\quad \mathrm{ESA}$ & $\mathrm{ESA}+$ linoleic acid \\
& & \\
& & \\
& & & \\
& &
\end{tabular}

\begin{tabular}{|c|c|c|c|c|}
\hline $\mathrm{H} 327 \bigcirc \times \mathrm{F} 5-28 \hat{\jmath} \ddagger$ & - & - & $\mathrm{PP}, \mathrm{P}^{++} \S$ & $\mathrm{S}, \mathrm{PP}, \mathrm{P}^{+++}$ \\
\hline $\mathrm{F} 5-289 \times \mathrm{H} 327 \hat{\jmath}$ & - & - & $\mathrm{PP}, \mathrm{P}^{+++}$ & $\mathrm{S}, \mathrm{PP}, \mathrm{P}^{+++}$ \\
\hline NRRL6404 $9 x$ & & & $\mathrm{~S}, \mathrm{PP}^{+}$ & $\mathrm{S}, \mathrm{PP}, \mathrm{P}^{+}$ \\
\hline VA3O $0^{\lambda}$ & & & & \\
\hline VA3O $P \mathrm{x}$ & & & $\mathrm{S}, \mathrm{PP}^{+}$ & $\mathrm{S}, \mathrm{PP}, \mathrm{P}^{+}$ \\
\hline NRRL6404へ & & & & \\
\hline W9 9 x Q412T & - & - & $\mathrm{S}, \mathrm{PP}, \mathrm{P}^{+++}$ & $\mathrm{S}, \mathrm{PP}, \mathrm{P}^{+++}$ \\
\hline Q412T $q \times$ W9 0 & - & - & $\mathrm{S}, \mathrm{PP}, \mathrm{P}^{+++}$ & $\mathrm{S}, \mathrm{PP}, \mathrm{P}^{+++}$ \\
\hline
\end{tabular}

${ }^{*}$ Observations presented in this table were made 60 days after recipient cultures had 595 been fertilized with donor strains

596 †OMM= Ophiostoma minimal medium (OMM; Bernier and Hubbes 1990); ESA= elm 597 sapwood agar (Brasier 1981). Linoleic acid was added to a final concentration of $6 \mu \mathrm{l}$ $598 \mathrm{~mL}^{-1}$. 
$599 \quad \ddagger$ Strains followed by $\uparrow$ and $\lesssim$ are recipients and donors, respectively.

600 §Semi-quantitative data are shown for perithecia. $+=$ a few; $++=$ moderate quantity;

$601+++=$ many perithecia was observed.

602

603

604

605

606

607

608

609

610

611

612

613

614

615

616 
617 Figure captions :

618 Figure 1. Production of reproductive structures in crosses between Dutch elm disease 619 fungi on solid Elm Sapwood Agar (ESA) media. A. Cross W9 $\propto$ x Q412T ${ }^{\wedge}$ yielded 620 synnemata, protoperithecia and perithecia on ESA supplemented with linoleic acid. B. 621 Protoperithecia and perithecia were obtained in cross $\mathrm{H} 327 q$ x $\mathrm{F} 5-28 \AA$ on solid ESA 622 supplemented with linoleic acid. C. Synnemata produced by cross VA3O 0 x 623 NRRL6404 ${ }^{\lambda}$ on ESA with linoleic acid. D. Only protoperithecia were formed in cross $624 \mathrm{H} 327$ $\times \mathrm{F} 5-28{ }^{\lambda}$ on ESA without linoleic acid. Large arrows indicate synnemata, 625 medium arrows perithecia, and small arrows protoperithecia.

626

627 Figure 2. Effect of linoleic acid on mycelium production in Dutch elm disease pathogens 628 in shake liquid Ophiostoma minimal medium (OMM) supplemented with arginine (A) or 629 proline (B). Strains were grown for 19h (white and black bars) and 24h (light gray and 630 dark gray bars). Treatments without linoleic acid (LA) are depicted as white and light 631 gray bars and with LA $(6 \mu \mathrm{lmL}-1)$ as black and dark gray bars. Values are means of five 632 replicates from a representative experiment. $P$ values are shown for comparison 633 between treatments for each combination of strain-period (19h or 24h) according to $t$ 634 test. (C) Yeast cells of O. novo-ulmi NRRL6404 after 24h of incubation in OMM with 635 proline (upper panel) and mycelium production of the same strain after $24 \mathrm{~h}$ in OMM with 636 proline and linoleic acid (lower panel). Scale bars $=20 \mu \mathrm{m}$.

637

638 

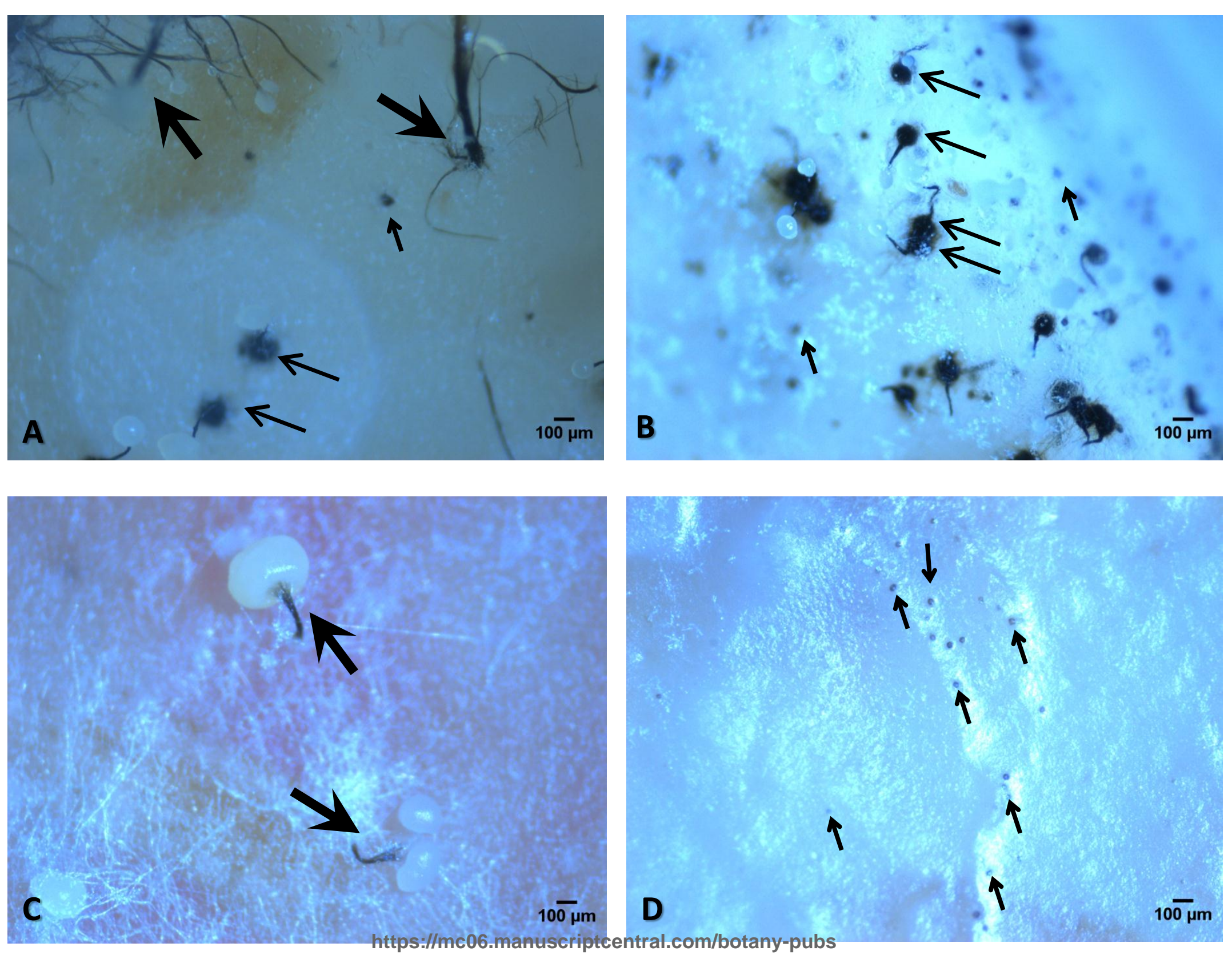

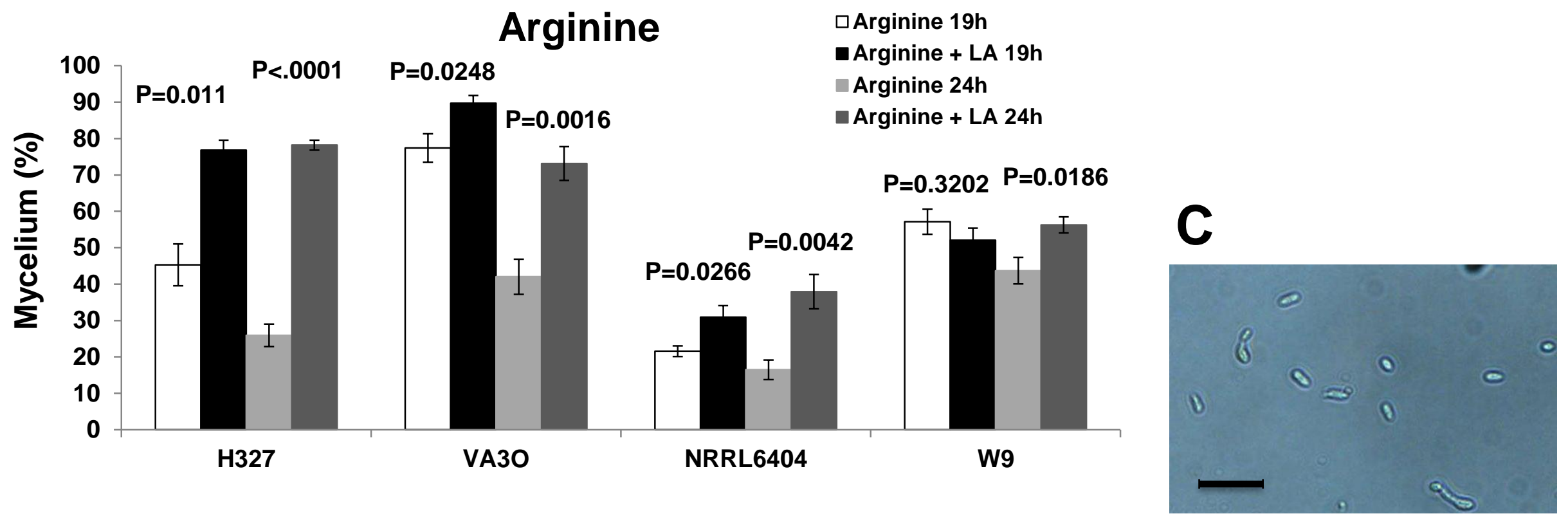

B
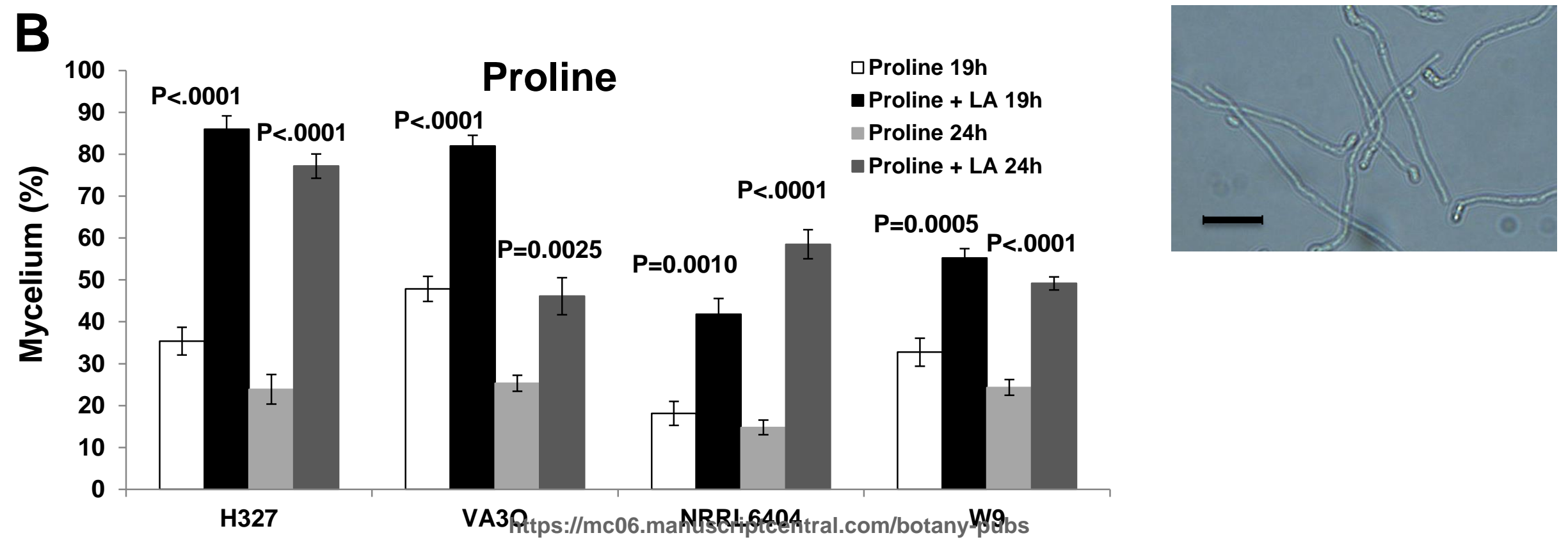